\title{
Endometrioma is a Responsible Factor for Reduced Ovarian Reserve
}

\author{
MOSAMMAT RASHIDA BEGUM ${ }^{1}$, MARIYA EHSAN ${ }^{2}$, NAZIA EHSAN ${ }^{3}$, FARHANA SHARMIN ${ }^{4}$, \\ FARZANA KHAN ${ }^{5}$, AURIN IFTEKAR AMIN ${ }^{6}$
}

\begin{abstract}
:
Objective (s): The aim of the study was to assess ovarian reserve (OR) of patients with endometrioma and to explore the differences of ovarian reserve in age matched group of infertile patients without endometrioma.

Materials and methods: This prospective analytic study was done in Infertility Care and Research Center, between January 2013 and December 2015 to assess the ovarian reserve of patients with endometrioma. During this period 105 patients of endometriosis with endometrioma were selected for study. Selection criteria were: no history of previous surgery, $<36$ years of age, no history of endocrine problems, no history of recent medical treatment for this condition within 6 months and no history of irregular menstruation. For ovarian reserve testing we assessed serum FSH, E2 and AMH. Patient of same age group who had no emdometrioma, no history of any surgery, no menstrual irregularity, endocrine disorder or any other medical diseases were taken as control to compare the ovarian reserve between these two groups. For control group also we did the same tests. Data was analyzed by SPSS package. One-way ANOVA test was done for test of significance. A p-value of $<0.05$ was considered as significant.
\end{abstract}

Results: There was no difference in characteristics of patients of both groups regarding age, type of infertility and duration of infertility. Size of the endometriotic cysts were variable and average diameter of cyst was $6.2 \pm 2.32 \mathrm{~cm}$. Most (58.10\%) of the cysts were unilateral. There is a significant difference of FSH and AMH level between the groups. FSH of endometrioma and non-endometrioma group was $7.9 \pm 1.17$ and $7.1 \pm 1.05 \mathrm{mlU} / \mathrm{mL}$ respectively with a $p$ value of 0.029. Similar difference was present in AMH level, which was $2.42 \pm .63$ and $2.98 \pm .88 \mathrm{ng} /$ $\mathrm{mL}$ in endometrioma and non-endometrioma group respectively with a $p$ value of 0.020 .

Conclusion: This small study shows a reduced ovarian reserve in patients with endometrioma in comparison to patients of same parameters without endometrioma. It suggests that there is an association of presence of ovarian endometrioma and reduced ovarian reserve

Key words: Endometrioma, Ovarian reserve

Introduction:

Female reproductive age is short because over time, oocytes decrease in quantity and quality and do not regenerate ${ }^{1}$. In early weeks of intrauterine life 6-7 million oocytes present in the ovary, which undergo continuous and profound apoptosis and atresia during intrauterine life and approximately 1-2 million oocytes are present at birth. Until puberty only 300,000500,000 oocytes remain in both ovaries. ${ }^{2}$ Different factors such as lifestyle, environment, genetics and medical issues, including endometriosis, ovarian cystectomy, oophorectomy, pelvic inflammatory

1. Chief Consultant, Infertility Care and Research Center

2. Ex Medical officer, Infertility Care and Research Center, MSc Student, University of Ontario, Canada

3. Ex Medical officer, Infertility Care and Research Center, MSc Student, University of Ontario, Canada

4. Medical officer, Infertility Care and Research Center

5. Senior Medical officer, Infertility Care and Research Center

6. Ex Medical officer, Infertility Care and Research Center, MSc Student, University of Ontario, Canada 
disease, chemotherapy, and radiotherapy reduce the quantity and quality of oocytes. ${ }^{3}$ Although this reproductive decline occurs with age, there is significant variation in fertility among women of similar age, which highlights the unpredictability and individuality of the reproductive aging process. ${ }^{4}$

The concept of "ovarian reserve" defines a woman's reproductive potential as a function of the number and quality of her remaining oocytes. ${ }^{1}$ The purpose of ovarian reserve testing is to assess the quality and quantity of the remaining oocytes in an attempt to predict reproductive potential and for discussing prognosis and recommending a treatment plan. When test results suggest decreased or diminished ovarian reserve, it is reasonable to counsel the woman that her window of opportunity to conceive may be shorter than anticipated, and attempting to conceive sooner rather than later is encouraged.

To make decision or planning of treatment in infertility with endometriosis is important in this regard. Endometriosis affects $0.8 \%-2 \%$ of women of reproductive age ${ }^{5-9}$ and $20-40 \%$ women with endometriosis have endometrioma. ${ }^{10-12}$ About $30-50 \%$ of women with endometriosis experience fertility problems and endometriomas are frequently encountered durinig infertility work-up. ${ }^{13-15}$ Based on the current evidence, treatment by laparoscopic ovarian cystectomy appears to be the method of choice. ${ }^{16-18}$ Despite the improvements in technique of laparoscopy and management of symptomatic patients with endometriomas, there is growing concern about the negative impact on ovarian reserve due to inadvertent removal or destruction of the healthy ovarian tissue adjacent to the pseudocapsule of the cyst. ${ }^{19-23}$ Several studies have suggested that ovaries with endometrioma may already have some damage and decreased ovarian reserve preceding surgery ${ }^{24-}$ ${ }^{26}$ Specifically, Kitajima et al. ${ }^{25}$ showed that the cortex of ovaries having endometrioma $>4 \mathrm{~cm}$ have fibrosis and concomitant loss of cortex-specific stroma, which leads to significantly lower follicular density compared with contralateral normal ovaries. Undertaking surgery on these ovaries further deteriorates ovarian reserve. So before taking decision of surgery it is important to assess ovarian reserve.

Purpose of this study was to assess ovarian reserve of patients with endometrioma and to explore the differences of ovarian reserve in age matched group of infertile patients without endometrioma.

\section{Materials and methods:}

This prospective analytic study was done in Infertility Care and Research Center a tertiary level infertility care center, between January 2013 and December 2015 to assess the ovarian reserve of patients with endometrioma. During this period 105 patients of endometriosis with endometrioma were selected for study. Only those patients were selected who had no history of previous surgery. Other inclusion criteria were all patients were under the age of 36 , there was no history of endocrine problems, no history of recent medical treatment for this condition within 6 months and no history of irregular menstruation. For ovarian reserve testing we assessed serum FSH, E2 and AMH. Ovarian volume measurement was not done as measuring ovarian volume with a cyst is not very informative. Antral follicle count of cystic ovary also was not done to avoid technical error of counting antral follicle with endometrioma. Moreover, it is proved that $\mathrm{AMH}$ is a very good predictor of ovarian reserve testing. ${ }^{27-30}$ So we have given emphasis on $\mathrm{AMH}$ as indicator of ovarian reserve. Patient of same age group who had no emdometrioma, no history of any surgery, no menstrual irregularity, endocrine disorder or any other medical diseases were taken as control to compare ovarian reserve parameters between these two groups. For control group also we did same tests like $\mathrm{FSH}, \mathrm{E} 2$ and $\mathrm{AMH}$ to assess ovarian reserve. $\mathrm{AMH}$ was done by a commercial enzyme-linked immunosorbent assay kit (ELISA, Beckman Coulter USA) and FSH, E2 was done by LIAISON automated analyzer. All the serum sample were immediately separated by centrifugation at $4^{0} \mathrm{C}$ for 15 minutes and stored at $-20^{\circ} \mathrm{C}$ until assay. Data was analyzed by SPSS package. One-way ANOVA test was done for test of significance. A p-value of $<0.05$ was considered as significant.

\section{Results:}

Characteristics of the patients of both groups are shown in the table I. There was no difference in characteristics regarding age, type of infertility and duration of infertility. Table II shows the characteristics of endometrioma. Size of the endometriotic cysts were varied and average diameter of cyst was $6.2 \pm 2.32$ $\mathrm{cm}$. Most $(58.10 \%)$ of the cysts were unilaterally distributed. Table III has shown the differences of ovarian reserve parameters between the patients with endometrioma and without endometrioma. There is a significant difference of $\mathrm{FSH}$ and $\mathrm{AMH}$ level between 
Table I

Characteristics of patients of both groups

\begin{tabular}{lcccccc}
\hline Characteristics & \multicolumn{2}{c}{ Endometrioma } & & \multicolumn{2}{c}{ No endometrioma } & \multirow{2}{*}{ Significance } \\
\cline { 2 - 3 } & Mean & \pm SD & & Mean & \pm SD & \\
\hline Age (Years) & 28.72 & \pm 3.45 & & 29.58 & \pm 3.89 & NS \\
Type of infertility & $\mathrm{N}$ & $\%$ & $\mathrm{~N}$ & $\%$ & \\
Primary & 72 & 68.58 & 75 & 71.42 & $\mathrm{NS}$ \\
Secondary & 33 & 31.42 & & 30 & 28.57 & $\mathrm{NS}$ \\
Duration of infertility & Mean & \pm SD & & Mean & \pm SD & \\
(Years) & 4.5 & \pm 1.28 & & 5.1 & \pm 1.92 & $\mathrm{NS}$ \\
\hline
\end{tabular}

Table-II

Characteristics of endometrioma

\begin{tabular}{lcc}
\hline & \multicolumn{2}{c}{ Endometrioma } \\
\cline { 2 - 3 } Characteristics & Mean & $\pm \mathrm{SD}$ \\
Size of the cyst $(\mathrm{cm})$ & 6.2 & 2.32 \\
Laterility & $\mathrm{N}$ & $\%$ \\
Unilateral & 61 & 58.10 \\
Bilateral & 44 & 41.90 \\
\hline
\end{tabular}

Table-III

Basal hormone of patients with endometrioma and without endometrioma

\begin{tabular}{|c|c|c|c|c|c|}
\hline \multirow[t]{2}{*}{ Hormones } & \multicolumn{2}{|c|}{ Endometrioma } & \multicolumn{2}{|c|}{ No-Endometrioma } & \multirow[t]{2}{*}{ Significance } \\
\hline & Mean & $\pm S D$ & Mean & \pm SD & \\
\hline $\mathrm{FSH} \mathrm{mlU} / \mathrm{mL}$ & 7.9 & \pm 1.17 & 7.1 & \pm 1.05 & 0.029 \\
\hline $\mathrm{E} 2 \mathrm{pg} / \mathrm{mL}$ & 48 & \pm 20.02 & 45 & \pm 21.22 & 0.293 \\
\hline $\mathrm{AMH} n g / \mathrm{mL}$ & 2.42 & \pm .63 & 2.98 & \pm .88 & 0.020 \\
\hline
\end{tabular}

the groups. FSH of endometrioma and nonendometrioma group was $7.9 \pm 1.17$ and $7.1 \pm 1.05$ $\mathrm{mIU} / \mathrm{mL}$ respectively with a $\mathrm{p}$ value of 0.029 . Similar difference exists in AMH level, which was $2.42 \pm .63$ and $2.98 \pm .88 \mathrm{ng} / \mathrm{mL}$ in endometrioma and nonendometrioma group respectively with a $p$ value of 0.020 . Though there was no statistically significant difference in $\mathrm{E} 2$ level of the groups.

\section{Discussion:}

This study shows that patients with endometrioma have relatively lower ovarian reserve in comparison to age matched control group. It indicates that endometriosis itself is responsible for reduction of ovarian reserve. $\mathrm{AMH}$ which is secreted by preantral and antral follicle reduces steadily with advancing age as number of follicle reduces by continuous atresia and apoptosis. A number of studies demonstrated that $\mathrm{AMH}$ was a stedier marker to predict residual ovarian function. ${ }^{27-30}$ Changes in serum AMH level in patients with endometriosis has been well documented. Remarkable declines in serum AMH were reported in patients with moderate to sever endometriosis, which was more pronounced in those with bilateral endometrioma. ${ }^{25,31-36}$ Ovaries with endometrioma may already have some damage with decreased ovarian reserve. ${ }^{24-26}$ Lower anti-mullerian hormone serum levels and association with the severity of the disease found in women with endometriosis. Till today a number of studies have shown that the presence of 
endometriosis has been shown to be associated with a decrease in the follicular ovarian reserve accompanied by a reduction in AMH levels. 25,31,37

Several mechanisms by which the endomterioma progressively affects the ovarian tissue have been identified. Colour Doppler transvaginal ultrsonography shows interstitial devascularization in the ovarian endometrioma bed and confirmed that fibrosis and miscrovascular injury were a potential cause of reduced follicle reserve. ${ }^{38}$ Kitajima et al in a recent study took biopsy of healthy cortex from ovaries affected by endometriomas $\geq 4 \mathrm{~cm}$ and contralateral ovaries without cysts and reported that cortex from ovaries with endometriomas contained significantly more morphologically atretic early follicle than cortex from contralateral ovaries without cysts. ${ }^{25}$ The content of cystic fluid has deleterious effect on the adjacent ovarian cortical tissue. Sanchez et al reported increased free iron level in endometriotic cystic fluid than normal serum iron level and iron level of other ovarian cyst. ${ }^{39}$ They concluded that sufficient evidences support the adverse effect of endometrial cystic fluid on the adjacent ovarian cortical tissue independent of the mere mechanical stretching owing to its fluid content.

In our study we found increased FSH and lowered $\mathrm{AMH}$ in endometrioma group, which is consistent with other studies. ${ }^{22} 40-45$ It has been known that elevated serum oestradiol in early follicular phase predicts poor ovarian reserve when undergoing in vitro fertilization. ${ }^{46-}$ 48 Chiang et al found significantly highest oestradiol level in endometriosis group without previous surgery and concluded that patients with endometriosis would have poor ovarian reserve. ${ }^{49}$ In our study we did not find any difference of E2 level between two groups. As $\mathrm{AMH}$ is the best predictor of ovarian reserve we focused on $\mathrm{AMH}$ level rather than $\mathrm{FSH}$ and E2. Increased E2 level suppress FSH level. So both E2 and FSH can't be increased simultaneously. We found significance difference in FSH level.

Now question arises that should we measure ovarian reserve in women with endometriotic cyst irrespective of the age of the patient? If so, why? Biochemical testing of ovarian reserve is expensive in the context of Bangladesh. So for young patients below the age of 30 years most of the gynaecologists of our country do not recommend to do the biochemical tests for ovarian reserve. We know standard treatment of endometrioma in infertility is surgical removal of the cyst and laparoscopy is the best option. But it has been documented that ovarian surgery may causes ovarian insufficiency. ${ }^{50}$ and it is well known that women with endometriotic cysts have an increased risk of ovarian insufficiency, particularly if bilateral cysts have been removed. 37, 51-53 Several mechanisms have been described to explain the quantitative alteration of ovarian reserve after cystectomy for endometrioma; accidental removal of healthy ovarian tissue during cystectomy, vascular compromise due to electrocoagulation, local inflammation and autoimmune reaction, expertise of the surgeon, extent of the disease and number of surgical interventions may have impact on ovarian reserve. Even at the hand of skilled surgeon there is a progressive decline of AMH after endometriotic cystectomy. ${ }^{54}$ Cyst drainage and coagulation cause less harm than cystectomy, but recurrence rate is higher than cystectomy. ${ }^{16,17}$ Recently surgeons are trying to modify the surgical technique to protect the ovarian reserve. Modified combined surgical technique for ovarian cystectomy in endometrioma is an approach to remove the endometrioma without increasing the recurrence rate and ovarian tissue damage. 55

Considering these facts it is very important to take the decision of modalities of treatment with endometrioma with already poor ovarian reserve. Whatever may be the age of the patient, reproductive life will go to an end if ovarian follicles are exhausted by one or more surgery. For infertile patients mode of treatment should be individualized according to the patients' status. So depending upon the ovarian reserve of the patient surgical removal of the cyst, aspiration of the cyst followed by down-regulation and ART or long down-regulation and ART should be offered. Pacchiarotti et al. concluded in their study that damage of endometriosis on ovarian reserve, leading to a form of incipient ovarian failure, which is considered as an early sign of advanced ovarian depletion in young women. So AMH could be used in the follow-up of patients with endometriosis, in order to assess promptly the decrease of ovarian reserve. ${ }^{34}$

In conclusion from findings of this small study it can be said that endometrioma itself might be associated with poor ovarian reserve of this population. So care should be taken for subsequent treatment plan and approach of surgery so that fertility prospect is not lost by treatment itself. It may be prudent to measure $\mathrm{AMH}$ levels preoperatively and delay/avoid surgical 
excision as far as possible if subsequent fertility is a concern. Further large scale studies are required to investigate whether the endometrioma related decline in ovarian reserve per se is progressive in nature and needs active treatment of infertility.

\section{References:}

1. Testing and interpreting measures of ovarian reserve: a committee opinion. Practice Committee of the American Society for Reproductive Medicine. Fertil Steril 2012;98:1407-15.

2. Faddy MJ, Gosden RG, GougeonA, Richardson SJ, Nelson JF. Accelerated disappearance of ovarian follicles in midlife: implications for forecasting menopause. Hum Reprod 1992;7:1342-46.

3. Female age-related fertility decline. Committee Opinion No. 589. American College of Obstetricians and Gynecologists. Obstet Gynecol 2014;123:719-21.

4. te Velde ER, Pearson PL. The variability of female reproductive ageing. Hum Reprod Update 2002;8:141-54.

5. Moen MH, Schei B. Epidemiology of endometriosis in a Norwegian county. Acta Obstet Gynecol Scand 1997;76:559-562.

6. Leibson CL, Good AE, Hass SL, Ransom J, Yawn BP, O'Fallon WM, Melton LJ 3rd.. Incidence and characterization of diagnosed endometriosis in a geographically defined population. Fertil Steril 2004;82:314-321.

7. Ballard KD, Seaman HE, de Vries CS, Wright JT. Can symptomatology help in the diagnosis of endometriosis? Findings from a national casecontrol study_Part 1. BJOG 2008;115:13821391.

8. Gylfason JT, Kristjansson KA, Sverrisdottir G, Jonsdottir K, Rafnsson V, Geirsson RT. Pelvic endometriosis diagnosed in an entire nation over 20 years. Am J Epidemiol 2010;172:237-243.

9. Abbas S, Ihle P, Koster I, Schubert I. Prevalence and incidence of diagnosed endometriosis and risk of endometriosis in patients with endometriosis-related symptoms: findings from a statutory health insurance-based cohort in Germany. Eur J Obstet Gynecol Reprod Biol 2012;160:79-83.
10. Jenkins S, Olive DL, Haney AF. Endometriosis: pathogenetic implications of the anatomic distribution. Obstet Gynecol 1986;67:335-338.

11. Redwine DB. Ovarian endometriosis: a marker for more extensive pelvic and intestinal disease. Fertil Steril 1999;72:310-315.

12. Vercellini $P$, Chapron $C$, De Giorgi $O$, Consonni D, Frontino G, Crosignani PG. Coagulation or excision of ovarian endometriomas? Am J Obstet Gynecol 2003;188:606-610.

13. Gelbaya TA, Gordts S, D'Hooghe TM, Gergolet $M$, Nardo LG. Management of endometrioma prior to IVF: compliance with ESHRE guidelines. Reprod Biomed Online 2010;21:325-330.

14. Raffi $F$, Metwally $M$, Amer $S$. The impact of excision of ovarian endometrioma on ovarian reserve: a systematic review and meta-analysis. J Clin Endocrinol Metab2012a;97:3146-3154.

15. Raffi F, Shaw RW, Amer SA. National survey of the current management of endometriomas in women undergoing assisted reproductive treatment. Hum Reprod2012b;27:2712-2719

16. Alborzi, S., Momtahan, M., Parsanezhad, M.E., Dehbashi, S., Zolghadri, J., and Alborzi, S. A prospective randomized study comparing laparoscopic ovarian cystectomy versus fenestration and coagulation in patients with endometriomas. Fertil Steril. 2004; 82: 16331637

17. Beretta, P., Franchi, M., Ghezzi, F., Busacca, M., Zupi, E., and Bolis, P. Randomized clinical trial of two laparoscopic treatments of endometriomas: cystectomy versus drainage and coagulation. Fertil Steril. 1998; 70: 11761180

18. Hart, R., Hickey, M., Maouris, P., Buckett, W., and Garry, R. Excisional surgery versus ablative surgery for ovarian endometriomata: a Cochrane Review. Hum Reprod. 2005; 20: 3000-3007.

19. Alborzi, S., Foroughinia, L., Kumar, P.V., Asadi, N., and Alborzi, S. A comparison of histopathologic findings of ovarian tissue inadvertently excised with endometrioma and other kinds of benign ovarian cyst in patients undergoing laparoscopy versus laparotomy. Fertil Steril. 2009; 92: 2004-2007 
20. Busacca, M. and Vignali, M. Endometrioma excision and ovarian reserve: A dangerous relation. J Minim Invasive Gynecool. 2008; 16: 142-148

21. Muzii, L., Bellati, F., Bianchi, A., Palaia, I., Manci, N., Zullo, M.A. et al. Laparoscopic stripping of endometriomas: a randomized trial on different surgical techniques. Part II: Pathological results. Hum Reprod. 2005; 20: 1987-1992.

22. Alborzi A, Keramati P, Younesi M, Samsami A, Dadras N. The impact of laparoscopic cystectomy on ovarian reserve in patients with unilateral and bilateral endometriomas Fertil Steril. 2014; 101(2):427-434.

23. Kwon Sk, Kim SH, Yun SC, Kim DY, KIM CH, Kang BM. Decline of serum antimüllerian hormone levels after laparoscopic ovarian cystectomy in endometrioma and other benign cysts: a prospective cohort study. Fertil Steril. 2014; 101(2): 435-441.

24. Schubert, B., Canis, M., Darcha, C., Artonne, C., Pouly, J.L., Déchelotte, P. et al. Human ovarian tissue from cortex surrounding benign cysts: a model to study ovarian tissue cryopreservation. Hum Reprod. 2005; 20: 1786-1792.

25. Kitajima, M., Defrère, S., Dolmans, M.M., Colette, S., Squifflet, J., Van Langendonckt, A. et al. Endometriomas as a possible cause of reduced ovarian reserve in women with endometriosis. Fertil Steril. 2011; 96: 685-691.

26. Maneschi, F., Marasa, L., Incadela, S., Mazzarese, M., and Zupi, E. Ovarian cortex surrounding benign neoplasms: a histologic study. Am J Obstet Gynecol. 1993; 169: 388-393.

27. Loh JS, MaheshwariA. Anti-Mullerian hormoneis it a crystal ball for predicting ovarian ageing? Hum Reprod. 2011;26(11):2925-32.

28. La Marca A, Sighinolfi G, Radi D, Argento C, Baraldi E, Artenisio AC, et al. Anti-Mullerian hormone $(\mathrm{AMH})$ as a predictive marker in assisted reproductive technology (ART). Hum Reprod Update. 2010;16(2):113-30.

29. Nelson SM, Anderson RA, Broekmans FJ, Raine-Fenning N, Fleming R, La Marca A. AntiMullerian hormone: clairvoyance or crystal clear? Hum Reprod. 2012;27(3):631-36.
30. Riggs RM, Duran EH, Baker MW, Kimble TD, Hobeika E, Yin L, et al. Assessment of ovarian reserve with anti-Müllerian hormone: a comparison of the predictive value of antiMüllerian hormone, follicle-stimulating hormone, inhibin B, and age. Am J Obstet Gynecol. 2008;199(2):202.e201-8.

31. Lemos NA, Arbo E, Scalco R, Weiler E, Rosa V, Cunha-Filho JS. Decreased anti-Müllerian hormone and altered ovarian follicular cohort in infertile patients with mild/minimal endometriosis. Fertil Steril. 2008;89(5):1064-8.

32. Shebl O, Ebner T, Sommergruber M, Sir A, Tews G. Anti muellerian hormone serum levels in women with endometriosis: a case-control study. Gynecol Endocrinol. 2009;25(11):713-36.

33. Kim JY, Jee BC, Suh CS, Kim SH. Preoperative serum anti-mullerian hormone level in women with ovarian endometrioma and mature cystic teratoma. Yonsei Med J. 2013;54(4):921-26.

34. Pacchiarotti A, Frati P, Milazzo GN, Catalano A, Gentile V, Moscarini M. Evaluation of serum antiMullerian hormone levels to assess the ovarian reserve in women with severe endometriosis. Eur J Obstet Gynecol Reprod Biol. 2014; 172:6264.

35. Uncu G, Kasapoglu I, Ozerkan K, Seyhan A, Oral Yilmaztepe A, Ata B. Prospective assessment of the impact of endometriomas and their removal on ovarian reserve and determinants of the rate of decline in ovarian reserve. Hum Reprod. 2013;28(8):2140-45.

36. Streuli I, de Ziegler D, Gayet V, Santulli P, Bijaoui $\mathrm{G}$, de Mouzon J, et al. In women with endometriosis anti-Müllerian hormone levels are decreased only in those with previous endometrioma surgery. Hum Reprod. 2012;27(11):3294-303.

37. Iwase A, Hirokawa W, Goto M, Takikawa S, Nagatomo Y, et al. Serum anti-Mullerian hormone level is a useful marker for evaluating the impact of laparoscopic cystectomy on ovarian reserve. Fertil and Steril 2010; 94: 2846-2849.

38. Quit J J, Liu MH, Zhang Z X, Chen L P, Yang Q.C, Liu H. B. Transvaginal colour Doppler sonography predicts ovarian interstitial fibrosis and microvascular injury in women with ovarian 
endometriotic cyst. Acta obstet. Gynecol. Scand. 2012;91:605-612.

39. Sanchez A.M, Vigano P, Somigliana E, PaninaBordignon, $P$ Vercellini, Candiani M. The distinguishing cellular and molecular features of the endometriotis ovarian cyst: from pathophysiology to the potential endometriomamediated damage to the ovary. Hum.Reprod. Update. 2014;20:217-230.

40. Lee, D.Y., Young Kim, N., Jae Kim, M., Yoon, B.K., and Chos, D. Effects of laparoscopic surgery on serum anti-mullerian hormone levels in reproductive-aged women with endometrioma. Gynecol Endocrinol. 2011; 27: 733-736

41. Chang, H.J., Han, S.H., Lee, J.R., Jee, B.C., Lee, B.I., Suh, C.S. et al. Impacts of laparoscopic cystectomy on ovarian reserve: serial changes of serum anti-Mullerian hormone level. Fertil Steril. 2010; 94: 343-349

42. Kitajima, M., Khan, K.N., Hiraki, K., Inoue, T., Fujishita, A., and Masuzaki, H. Changes in serum anti-Mullerian hormone levels may predict damage to residual normal ovarian tissue after laparoscopic surgery for women with ovarian endometrioma. Fertil Steril. 2011; 95: 2589-2591

43. Hwu, Y.M., Wu, F.S., Li, S.H., Sun, F.J., Lin, M.H., and Lee, R.K. The impact of endometrioma and laparoscopic cystectomy on serum antiMullerian hormone levels. Reprod Biol Endocrinol. 2011; 9: 80

44. Biacchiardi, C.P., Piane, L.D., Camanni, M., Deltetto, F., Delpiano, E.M., Marchino, G.L. et al. Laparoscopic stripping of endometriomas negatively affects ovarian follicular reserve even if performed by experienced surgeons. Reprod Biomed Online. 2011; 23: 740-746.

45. Sugita, A., Iwase, A., Goto, M., Nakahara, T., Nakamura, T., Kondo, M. et al. One-year followup of serum antimüllerian hormone levels in patients with cystectomy: are different sequential changes due to different mechanisms causing damage to the ovarian reserve?Fertil Steril. 2013; 100: 516-522.
46. Sharara FI, Scott Jr RT, Seifer DB. The detection of diminished ovarian reserve in infertile women. Am J Obstet Gynecol. 1998;179(3):804-12.

47. Broekmans F, Kwee J, Hendriks D, Mol B, Lambalk C. A systematic review of tests predicting ovarian reserve and IVF outcome. Hum Reprod Update. 2006;12(6):685-718.

48. Sills ES, Alper MM, Walsh APH. Ovarian reserve screening in infertility: Practical applications and theoretical directions for research. Eur J Obstet Gynecol Reprod Biol. 2009;146(1):30-6.

49. Hsin-Ju Chiang, Pin-Yao Lin, Fu-Jen Huang, FuTsai Kung, Yu-Ju Lin, Pei-Hsun Sung and KuoChung Lan The impact of previous ovarian surgery on ovarian reserve in patients with endometriosis. BMC Women's Health.201515:74 DOI: 10.1186/ s12905-015-0230-1

50. De Vos M, Devroey P, Fauser BC. Primary ovarian insufficiency. Lancet 2010;376: 911-921.

51. Benaglia L, Somigliana E, Vighi V, Ragni G, Vercellini $P$, et al. Rate of severe ovarian damage following surgery for endometriomas. Human reproduction 2010;25: 678-682.

52. Busacca M, Riparini J, Somigliana E, Oggioni G, Izzo S, et al. Postsurgical ovarian failure after laparoscopic excision of bilateral endometriomas. American journal of obstetrics and gynecology 2006; 195: 421-425.

53. Welt CK. Primary ovarian insufficiency: a more accurate term for premature ovarian failure. Clinical endocrinology 2008;68: 499-509.

54. Celik HG, Dogan e, Okyay E, Ulukus C, Saatli B, Uysal S, Koyuncuoglu M. Effect of laparoscopic excision of endometriomas on ovarian reserve: serial changes in the serum antimullerian hormone levels. Fertil Steril. 2012;97(6):1472-1478.

55. Unlu Cihat and Yildirm G. Ovarian cystectomy in endometriomas: Combined approach. J Turk Ger Gynecol Assoc. 2014; 15(3): 177-189. 